\title{
Preparation and Characterization of Zinc Oxide (Zno)/Polymethyl Methacrylate (PMMA) Nanocomposites
}

\author{
Jayashree Bagawade \\ Assistant Professor, Department of Physics, Vidya Pratishthan's Arts, Science and Commerce College, \\ Vidyanagari, Baramati, Dist. Pune- 413113 MS, India
}

\begin{abstract}
A series of novel zinc oxide / Poly (methyl methacrylate) nanocomposite films with different $\mathrm{ZnO}$ contents were prepared through inclusion of pre-synthesized zinc oxide nanoparticles. The physical composition and morphology of the as-prepared nanocomposites were studied by XRD and TEM. The TEM analyses revealed that the zinc oxide nanoparticles have a particle size of $\sim 3-5 \mathrm{~nm}$. Xray diffraction proved the presence of the amorphous PMMA in the nanocomposites. The intermolecular interactions within the polymer nanocomposites were explored by FTIR and XRD. FTIR spectra confirmed the dispersion of the zinc oxide nanoparticles in the Poly (methyl methacrylate) i.e. PMMA matrices. The UV-Vis absorption measurements of the ZnO/PMMA nanocomposites proved their potential optical properties.
\end{abstract}

KEYWORDS: ZnO, poly (methyl methacrylate); nanocomposites; synthesis; characterization

\section{INTRODUCTION}

The dispersal of nanosized inorganic fillers into polymer medium to form polymer nanocomposites has drawn vast interest in current years [1]. A variety of inorganic filler/polymer nanocomposites will reveal excellent amazing properties, which deeply vary from that of usual materials and thereby wide applications in various areas [2-5]. It creates a novel cost-effective way to obtain preferred high performance materials [6]. $\mathrm{ZnO}$ was often selected as the inorganic constituents in the composite preparation because of its outstanding differentiated properties in optics, photonics and electronics. It has a high exciton binding energy (60 meV), wide bandgap energy $(3.4 \mathrm{eV})$ at room temperature. Furthermore, $\mathrm{ZnO}$ can be simply obtained through wet chemistry, which offers it to achieve uniform dispersion in polymer matrices through solution mixing [7-8]. PMMA (Polymethyl methacrylate) has been a popular choice for the preparation of polymer-inorganic composites and is selected as a supporting matrix in the current study because it is striking due to its light weight, smoothness, flexibility, environmental durability, high clearness, light transmission, milder processing conditions and biocompatibility. Besides it is a versatile polymeric material hence extensively used to make windows, eye contact \& camera lenses along with other optical apparatus \& many imaging and non-imaging microelectronic applications [4, 9]. A number of studies have accounted on the preparation of the zinc oxide -polymer nanocomposites [10-14]. The reported methods to incorporate the nano $\mathrm{ZnO}$ into a PMMA matrix include ex situ methods, or polymerization of methyl methacrylate monomers in the presence of the nanoparticles [15-18]. Attaining superior dispersal steadiness is of high significance for the preparation of uniform ZnO/PMMA nanocomposites. In this research work, we effectively introduced previously synthesized consistent and fine quantum-size zinc oxide nanoparticles into a PMMA polymer matrix to prepare a series of steady ZnO/PMMA nanocomposite films with three dissimilar concentrations. $\mathrm{ZnO}$ nanoparticles and the $\mathrm{ZnO} / \mathrm{PMMA}$ nanocomposites were characterized by using X-ray diffraction (XRD), Fourier transform infrared (FTIR) spectroscopy, transmission electron microscopy (TEM), and UV-visible spectroscopy.

\section{EXPERIMENTAL}

In this study, a simple solution-mixing method was used to prepare ZnO/PMMA nanocomposites with three different concentrations. Basically, zinc oxide nanoparticles in methanol were prepared by using zinc chloride and $\mathrm{NaOH}$ as precursors. We have in advance reported a easy method to produce $\mathrm{ZnO}$ nanoparticles in methanol with sizes varying from $~ 3-5 \mathrm{~nm}$ [19]. After washing the zinc oxide nanoparticles are redispersed in methanol for the preparation of ZnO/PMMA nanocomposites. Poly (methyl methacrylate),(PMMA) was first dissolved in acetone and dispersion of $\mathrm{ZnO}$ nanoparticles in methanol was added rapidly to this 


\section{International Journal of Current Science Research and Review}

ISSN: 2581-8341

Volume 04 Issue 04 April 2021

DOI: 10.47191/ijesrr/V4-i4-01, Impact Factor: 5.825

IJCSRR@ 2021

Www.ijcsrr.org

solution with continuous stirring for 60 minutes to obtain homogeneous solution. The final solution was then used as coating solution and deposited on Si wafers. It was spread into a Petri dish and the solvents are evaporated under vacuum to obtain the films. ZnO-PMMA nanocomposities with $\mathrm{ZnO}$ to PMMA molar ratios of 1:1, 2:1 and 5:1 were prepared. For reference, precise PMMA film was prepared by casting PMMA/ acetone solution into a dish, then heated at $100^{\circ} \mathrm{C}$ under vacuum for $\sim 2 \mathrm{~h}$ to get rid of any solvent cached in the polymer.

\section{RESULTS AND DISCUSSIONS}

The size and morphology of the zinc oxide nanoparticles were examined using TEM which shows the occurrence of spherical monodispersed particles with $\sim 3$ to $5 \mathrm{~nm}$ in size[19]. The UV-vis spectra of zinc oxide nanoparticles, PMMA and ZnO/PMMA nanocomposite films were recorded. Figure 1 plots the absorption spectra of zinc oxide nanoparticles and ZnO-PMMA nanocomposites with three different weight percentages of zinc oxide nanoparticles in PMMA.

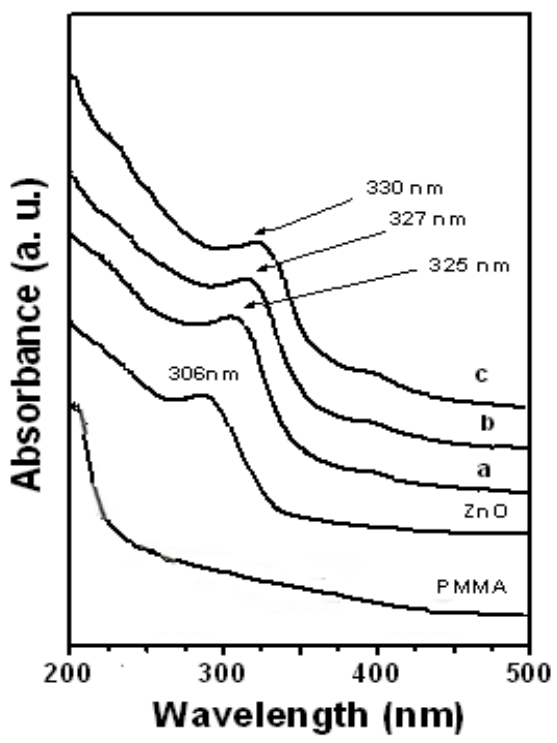

Figure 1. UV-Vis absorption spectra of $\mathrm{ZnO}$ nanoparticles, PMMA and ZnO/PMMA nanocomposite films with different ratios (a) $1: 1$ (b) $2: 1$ (c) $5: 1$

The UV-Vis absorption spectrum of $\mathrm{ZnO}$ nanoparticles reveals a well-defined exciton band at $\sim 306 \mathrm{~nm}$ and a blue shift compared with the bulk excition absorption $(\sim 372 \mathrm{~nm})$. The nanocomposite films absorb UV light .On the other hand, PMMA film does not soak up UV light down to $300 \mathrm{~nm}$ in wavelength, while. At the same time, the nanocomposites had a similar absorption in the visible region. It shows that all the nanocomposites are highly clear in the visible region. In addition, it was seen from the figure that the spectra also show redshifting of the onset wavelength as the $\mathrm{ZnO}$ concentration in PMMA increases. The absorption peak shifts from $\sim 306 \mathrm{~nm}$ to $\sim 330 \mathrm{~nm}$. UV absorbance increased as the nano $\mathrm{ZnO}$ content increased in composites. The more $\mathrm{ZnO}$ nanoparticles in PMMA, the more UV light is absorbed. Relatively strong absorbance in the UV region and small absorbance at the visible region, that means a typical optical property of the combination of visual transparency and UV filters closed to the visible waveleng th which was observed for the nanocomposite films. The nano $\mathrm{ZnO}$ particles in composites could enhance the UV shielding properties of the polymers. Also it can be used as UV filters in optical materials [20]. The presence of excitonic peak indicates the high crystallinity of dispersed $\mathrm{ZnO}$ nanoparticles inside PMMA. 


\section{International Journal of Current Science Research and Review}

ISSN: 2581-8341

Volume 04 Issue 04 April 2021

DOI: 10.47191/ijcsrr/V4-i4-01, Impact Factor: 5.825

IJCSRR@ 2021

Www.ijesrr.org

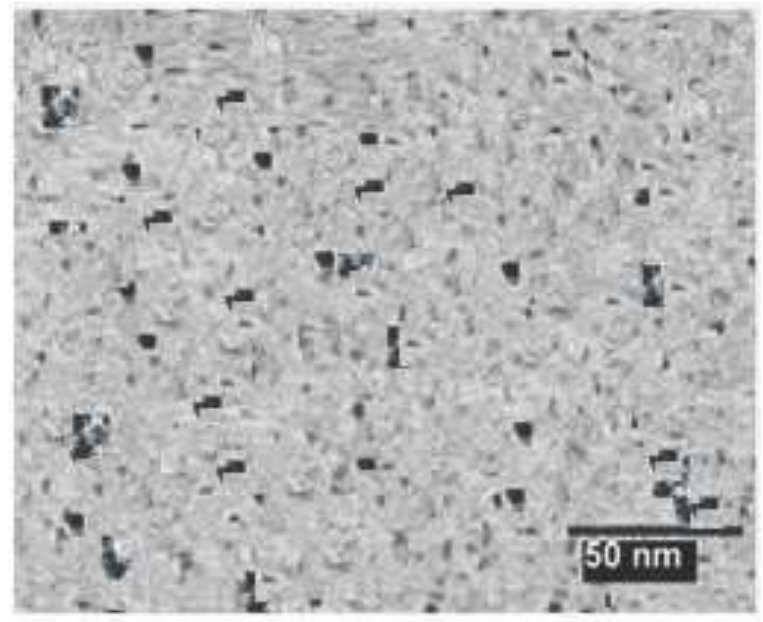

Figure 2. TEM image of $\mathrm{ZnO} / \mathrm{PMMA}$ nanocomposite film with ratio 2:1

Figure 2 shows the TEM image of the of zinc oxide-poly methyl methylacrylate nanocomposite film having $\mathrm{ZnO}$ concentration ratio 2:1. According to the HR-TEM images, the average aggregate sizes are estimated to be less than 50 nm for the nanocomposite films. The $\mathrm{ZnO}$ nanoparticles with a diameter of $\sim 3-5 \mathrm{~nm}$ distribute uniformly. The $\mathrm{ZnO}$ nanoparticles were well dispersed in an amorphous phase of PMMA matrix indicating that the polymer matrix plays an important role in stabilizing and dispersing the nanoparticles. From the UV-Vis absorption spectrum and EMA formula, the average size of the zinc oxide nanoparticles in $\mathrm{ZnO} / \mathrm{PMMA}$ nanocomposite film was estimated to be about $\sim 3.3 \mathrm{~nm}$ to $\sim 4.2 \mathrm{~nm}$. This result is in fine agreement with that of the TEM study. The XRD prototype of bare zinc oxide nanoparticles also proves this result. X-ray diffraction measurements were carried out on $\mathrm{ZnO}$ nanoparticles in the powder form. The X-ray diffraction patterns of nano $\mathrm{ZnO} \& \mathrm{ZnO} / \mathrm{PMMA}$ nanocomposite films were measured to examine the change of $\mathrm{ZnO}$ structure after polymerization.

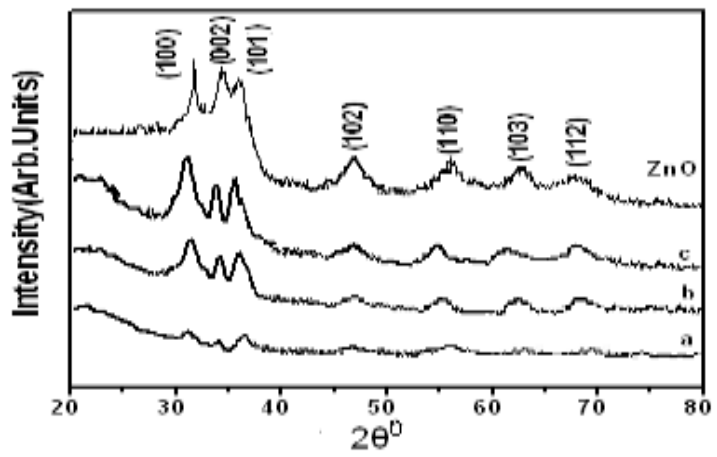

Figure 3. XRD spectra of $\mathrm{ZnO}$ nanoparticles, $\mathrm{ZnO} / \mathrm{PMMA}$ nanocomposite films with different ratios (a) $1: 1$ (b) 2:1 (c) 5:1

Figure 3 shows typical X-ray diffractions of $\mathrm{ZnO}$ nanoparticles and zinc oxide - poly methyl methacrylate nanocomposite films.

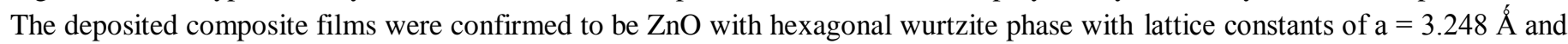
5.199 Á. The diffraction peaks corresponding to (100), (002) (101) (102), (110) (103) and (112) planes are present. The enlargement of the $\mathrm{ZnO}$ peaks is due to the small particle size. The average particle size (D) calculated using the Scherer formula is $\sim 3.5 \mathrm{~nm}$ for $\mathrm{ZnO}$ nanoparticles and the crystal size varies from $4.5 \mathrm{~nm}$ to $4.8 \mathrm{~nm}$ for $\mathrm{ZnO}$-PMMA nanocomposites as the nano $\mathrm{ZnO}$ content increased in the composites. All these results are consistent with UV-Vis spectral observations. However these diffraction peaks were not plainly viewed in the XRD patterns of $\mathrm{ZnO}$-polymer nanocomposites for sample ' $\mathrm{a}$ ' due to the lower $\mathrm{ZnO}$ content. As the $\mathrm{ZnO}$ nps concentration increases (sample ' $\mathrm{b}$ ' and ' $c$ ') the peaks were clearly observed. It was observed that the peak places and their relative intensities changed a little with varying the concentration of nano $\mathrm{ZnO}$. We used FTIR measurements to find out the actual amount of nano $\mathrm{ZnO}$ incorporated in nanocomposite films as well as interaction of $\mathrm{ZnO}$ with PMMA. Figure 4 exhibits the 


\section{International Journal of Current Science Research and Review}

ISSN: 2581-8341

Volume 04 Issue 04 April 2021

DOI: 10.47191/ijcsrr/V4-i4-01, Impact Factor: 5.825

IJCSRR@ 2021

www.ijcsrr.org

Transmission Infrared spectra (FTIR) spectra of ZnO, Pure PMMA and ZnO/PMMA nanocomposites over the range $4000-400 \mathrm{~cm}^{-}$

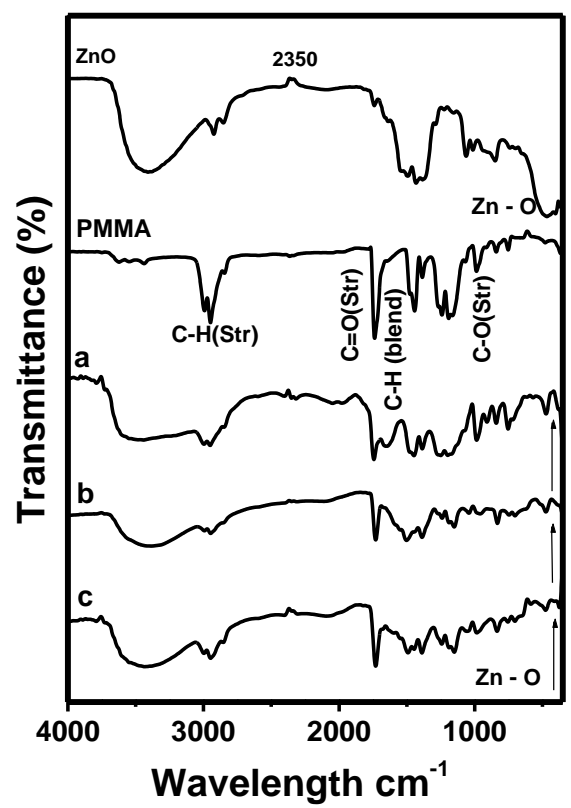

Figure 4. FTIR spectra of $\mathrm{ZnO}$ nanoparticles, PMMA and $\mathrm{ZnO} / \mathrm{PMMAnanocomposite} \mathrm{films} \mathrm{with} \mathrm{different} \mathrm{ratios} \mathrm{(a)} \mathrm{1:1} \mathrm{(b)} \mathrm{2:1}$

(c) $5: 1$

A broad absorption centered in the range $3400-3550 \mathrm{~cm}^{-1}$ was observed for all thin films and is assigned to $-\mathrm{OH}$ stretching. The strong absorption $\mathrm{C}=\mathrm{O}$ stretching peak of $\mathrm{PMMcm}^{-1}$ was observed for all thin films and is assigned to $-\mathrm{OH}$ stretching. The strong absorption $\mathrm{C}=\mathrm{O}$ stretching peak of PMMA is at $\sim 1730 \mathrm{~cm}^{-1}$. All the composite films exhibit the characteristic absorption peaks of $\sim 1730-1732 \mathrm{~cm}^{-1}$ and $\sim 2950 \mathrm{~cm}^{-1}$ which are caused by the stretching vibration bands of $\mathrm{C}=\mathrm{O}$ and $\mathrm{C}-\mathrm{H}$ bonds in the PMMA segments respectively. The intensity of these bands are found to be stronger as the nano $\mathrm{ZnO}$ content increases in the films. The peaks at $\sim 1149$ and $1192 \mathrm{~cm}^{-1}$ are owing to the C-H twists and $\sim 1242$ and $\sim 1269 \mathrm{~cm}^{-1}$ crests represent C-C-O stretch paired with C$\mathrm{O}$ stretch in Poly (methyl methacrylate). The absorbance at $\sim 1400-1500 \mathrm{~cm}^{-1}$. and $\sim 2800-3000 \mathrm{~cm}^{-1}$ regions that are feature of CHx bending and stretching respectively [21]. The crest at about $2358 \mathrm{~cm}^{-1}$ occurs from the $\mathrm{CO}_{2}$ atmosphere. It is proved from FTIR that the absorption bands of $\mathrm{ZnO}$ surface slowly increase in intensity with rising nano $\mathrm{ZnO}$ content. Compared with the infrared spectra of the pure PMMA, every characteristic bond becomes stronger or weaker with small shifts. The changes of infrared bands for PMMA in the hybrid film should be featured to well-built columbic interaction between $\mathrm{ZnO}$ and polymeric matrix. $\mathrm{Zn}-\mathrm{O}$ bond is also present given by the peak in the region $\sim 420-470 \mathrm{~cm}^{-1}$.

\section{CONCLUSIONS}

ZnO/PMMA nanocomposites were successfully prepared by solution casting with the reinforcement of zinc oxide nanoparticles synthesized by a simple chemical route. All of the prepared nanocomposites showed a reasonably good interaction between zinc oxide nanoparticles and the Polymer matrix. The formation of zinc oxide nanoparticles was determined by TEM and UV-Vis spectroscopy. Zinc oxide nanoparticles were found to be well dispersed in polymer matrices as observed from TEM images and they remained at the original size $\sim(3-5 \mathrm{~nm})$ before immobilization The onset of the UV absorption from the nanocomposites reveal red shifting as the $\mathrm{ZnO}$ concentration increases.. The nanocomposites were characterized by FTIR spectroscopy and XRD techniques. The IR measurements clearly implied that the polymer chains were well implanted onto zinc oxide nanoparticles surface. The obtained results indicate that the composite particles have potentially remarkable features of interest. In addition, due to the quantum confinement properties of $\mathrm{ZnO}$ nanoparticles, the use of these nanocomposites can be further extended to study various properties. 


\section{International Journal of Current Science Research and Review}

ISSN: 2581-8341

Volume 04 Issue 04 April 2021

DOI: 10.47191/ijcsrr/V4-i4-01, Impact Factor: 5.825

IJCSRR@ 2021

www.ijesrr.org

\section{REFERENCES}

1. MacLachlan M J, Manners I and Ozin G A, 'New (Inter) Faces: Polym19.ers and Inorganic Materials, Adv. Mater.12,2000,pp. 675.

2. Nase M, Langer B, Schumacher S, Grellmann W,Toughness optimization of glass-fiber reinforced PA6/PA66-based composites: effect of matrix composition and colorants, J Appl Polym Sci, 111,2009.pp 2245-2252.

3. Bagheri R, Liauw CM, Allen NS, Factors affecting the performance of montmorillonite/magnesium hydroxide/poly (propylene) ternary composites, Macromol Mater Eng, 2008,pp. 293.

4. Song, H., \& Lee, S., 'Photoluminescent (CdSe)ZnS quantum dot- PMMA polymer composite thin films in the visible spectral range, Nanotechnology 18, ,2007,pp. 55402.

5. Shanghua Li, Meng Meng Lin, Muhammet S. Toprak, Nanocomposites of polymer and inorganic nanoparticles for optical and magnetic applications, Nano Reviews, 2010,pp 1: 5214,

6. Kickelbick G, 'concepts for the incorporation of Inorganic building blocks into organic polymers on a nanoscale' Progress in Polym. Sci. 28, 2003, pp. 83-114.

7. Wang Z .L., 'Zinc oxide nanostructures: Growth, Propeties and Applications', J. Phys.: Condens. Matter 16, 2004, pp. $29-58$.

8. ] Look D C 2006 Progress in ZnO materials and devices. J. Elec.Mater. 35 (6), pp. 1299-305.

9. Lin H, Day DE, Stoffer JO Optical and Mechanical properties of optically transparent poly (methyl methacrylate) composites. Polym Eng Sci 32: 1992, pp. 344-50.

10. Schwartz et al. Antibacterial surface coatings from zinc oxide nanoparticles embedded in poly ( $\mathrm{N}$-isopropylacrylamide) hydrogel surface layers. Adv. Func. Mater. 22, 2012 pp. 2376-2386.

11. Nicolay, A. Elaboration and characterization of a multifunctional silane/ZnO hybrid nanocomposite coating. Appl. Surf. Sci. 327, 2015, pp. 379-388.

12. Todorova, N. Photocatalytic NOx oxidation over modified $\mathrm{ZnO} / \mathrm{TiO} 2$ thin films. Catal. Today 252, 2015, pp. 41-46.

13. Podasca, V. E., Buruiana, T. \& Buruiana, E. C. UV-cured polymeric films containing $\mathrm{ZnO}$ and silver nanoparticles with UV-vis lightassisted photocatalytic activity. Appl. Surf. Sci. 377 2016, pp. 262-273.

14. Yuan, X., Xu, W., Huang, F., Chen, D. \& Wei, Q. Polyester fabric coated with Ag/ZnO composite film by magnetron sputtering. Appl.Surf. Sci. 390, (2016),pp. 863-869.

15. Khrenov V, Klapper M, Koch M and Mullen K, 'Surface Functionalized ZnO Particles Designed for the Use in Transparent Nanocomposites',Macromol. Chem. Phys. 2062005 pp. 95-101.

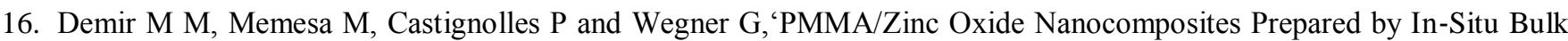
Polymerization', Macromol. Rapid Commun. 27 7, 2006 pp. 63-70.

17. Becheri A, Dürr M, Nostro PLo, Baglioni P, 'Synthesis and characterization of zinc oxide nanoparticles: Application to textiles as UV-absorbers. J Nano $p$ particle Res 10: 6,2008. pp. 79-89.

18. Demir, M. M., Castignolles, P., Akbey, U. \& Wegner, G. In-situ bulk polymerization of diluite particle/MMA dispersions.Macromolecules 40, (2007). pp. 4190-4198

19. Jayashri Bagawade,Structural and Spectroscopic Study of zinc oxide $(\mathrm{ZnO})$ nanoparticles, Global Journal of Engineering Science and Research, 6(4), 2019,pp. 113-117.

20. E.Tang, G.cheng, X.Pang, X.Ma, F. Xing, 'Synthesis of nano-ZnO/poly(methyl methacrylate) composite microsphere through emulsion polymerization and its UV-shielding property'Colloid Polym Sci. 284 (4),2006,pp. 422-428.

21. Wang W, Liu J, Yu X, Yang G., 'Transparent poly(methyl methacrylate)/ZnO nanocomposites based on $\mathrm{KH} 570$ surface modified ZnO quantum dots', J Nanosci Nanotech.. 10(8) (2010) 5196-201

Cite this Article: Jayashree Bagawade (2021). Preparation and Characterization of Zinc Oxide (Zno)/Polymethyl Methacrylate (PMMA) Nanocomposites. International Journal of Current Science Research and Review, 4(4), 246-250 